\title{
Calculation of Sedimentation at Sempor Reservoirs in 2018 Using Modified Universal Soil Loss Equation Method (MUSLE)
}

\author{
Septi Arini ${ }^{1}$, Yulaikhah ${ }^{2}$, Bambang Kun Cahyono ${ }^{2}$ \\ ${ }^{1}$ Alumni Departemen Teknik Geodesi FT-UGM, Indonesia \\ 2 Staf Pengajar Departemen Teknik Geodesi FT-UGM, Indonesia
}

\section{Article History:}

Received 4 November 2019

Received in revised form 20 December 2019

Accepted 23 December 2019

Available online 30 December 2019

\section{Keywords:}

Daerah Aliran Sungai, MUSLE, Laju

Sedimentasi, Sempor

\section{Corresponding Author:}

Yulaikhah

Email: yulaikhah@ugm.ac.id

\begin{abstract}
Sempor Reservoir located in the Telomoyo River Basin in the Serayu River region is categorized as one of the priority watersheds based on the 2015-2019 Strategic Plan of the Ministry of Environment and Forestry. Priority watershed is a watershed that is getting more attention in controlling water quality, including sedimentation. Monitoring and management activities of the watershed are needed in order to get an optimal operation of the reservoir. One of the monitoring and management activities of the Sempor Watershed is the sedimentation rate calculation. In this research, the sedimentation rate calculates using the MUSLE method. The Sempor watershed boundary is defined through the delineation of DEM and satellite images data. The calculation of sedimentation is obtained by several factors, including runoff parameter, erodibility, length and slope, land cover, and conservation. The calculation is performed by a Geographic Information System (GIS) method through analysis of soil type maps, length and slope maps, land cover, and conservation maps. Based on the calculation result, the Sempor Reservoir has a sedimentation rate of $166.173,500$ tons/year or 3,7259 mm/year in thickness. According to the provisions of the Ministry of Forestry in 2009, the sedimentation thickness rate of the reservoir is categorized in the medium class. The river as one of the potential means of sediment transport contributes to the rate of sediment thickness of $3,7256 \mathrm{~mm} /$ year, while for areas outside the river coverage it only 0.0003 $\mathrm{mm} /$ year.
\end{abstract}

(C) Author(s) 2019. This is an open access article under the Creative Commons Attribution-ShareAlike 4.0 International License (CC BY-SA 4.0).

\section{Pendahuluan}

Salah satu peristiwa alam yang berpengaruh terhadap kondisi Daerah Aliran Sungai (DAS) ialah erosi. Erosi adalah berpindahnya partikel tanah atau bagian tanah dari suatu tempat diangkut oleh air atau angin (Arsyad, 2010). Partikel tanah yang mengalami erosi berkumpul pada tempat lain dikenal dengan sedimen atau endapan, sedangkan prosesnya dinamakan sedimentasi. Di daerah tropis biasanya penyebab utama erosi adalah air hujan (Banuwa, 2013). Erosi pada DAS berbanding lurus dengan laju sedimentasi pada waduk.

Sedimentasi menyebabkan tampungan air pada waduk berkurang sehingga menyebabkan umur waduk lebih singkat dari rencana. Untuk mengurangi dampak tersebut diperlukan manajemen DAS yang terpadu dan teratur. Salah satu kegiatan untuk mengurangi dampak sedimentasi yaitu dengan mengidentifikasi perubahan- perubahan yang terjadi terhadap indikator fungsi hidrologi DAS. Sebagai wujud komitmen pemerintah dalam upaya pencegahan dampak tersebut maka ditetapkan 15 DAS prioritas pada tahun 2015-2019 oleh Kementerian Lingkungan Hidup dan Kehutanan (KLHK). Salah satu DAS prioritas ialah DAS Serayu, induk dari DAS Telomoyo. DAS Telomoyo merupakan daerah tangkapan air Waduk Sempor. Waduk Sempor digunakan untuk kegiatan pengairan, industri, domestik dan Pembangkit Listrik Tenaga Air (PLTA). Akan tetapi PLTA tersebut tidak bisa beropersi maksimal dikarenakan sedimentasi yang terjadi.

Sedimentasi pada Waduk Sempor didentifikasi dengan adanya perbedaan tampilan pada citra yang ditangkap atau direkam pada 2 musim yang berbeda. Sedimentasi mempengaruhi usia efektif layanan waduk dan berdampak pada terganggunya aktivitas akibat pendangkalan waduk, 
oleh karena itu diperlukan identifikasi dan perhitungan sedimentasi dalam rangka perawatan dan manajemen waduk. Terkait dengan hal tersebut, maka paper ini menghitung besarnya sedimentasi yang terjadi di Waduk Sempor khususnya pada tahun 2018.

\section{Data dan Metodologi}

\subsection{Data dan Lokasi}

Lokasi kegiatan dilaksanakan di DAS Waduk Sempor, Kebumen, Jawa Tengah, yang secara geografis berada pada $109^{\circ} 28^{\circ} 23^{\circ} \mathrm{BT}-109^{\circ} 30^{\circ} 35^{\circ} \mathrm{BT}$ dan $7^{\circ} 32^{\circ} 22^{\circ} \mathrm{LS}-7^{\circ} 34^{\circ}$ $01^{\circ}$ LS. DAS Waduk Sempor ditunjukkan pada Gambar 2.1.

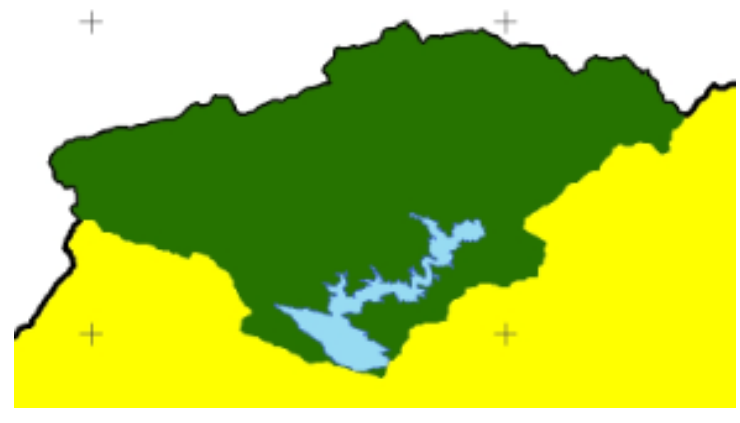

Gambar 2.1. DAS Waduk Sempor

Area kegiatan berada di DAS Waduk Sempor yang merupakan bagian dari DAS Makro Telomoyo pada Gambar 2.1 dengan luas area kegiatan $43,3 \mathrm{~km}^{2}$.

Data yang digunakan berupa data vektor dan raster terdiri atas:

1. Batas Waduk Sempor, diperoleh dari hasil evaluasi data DEMNAS dan digitasi batas waduk berdasarkan kenampakan pada Google Earth. Citra yang dipilih adalah citra tahun 2010 yang memiliki cakupan air terluas (sesuai elevasi DEMNAS), dan minimum cloudcover. Hasil digitasi batas Waduk Sempor pada tahun 2010 pada Gambar 2.2.

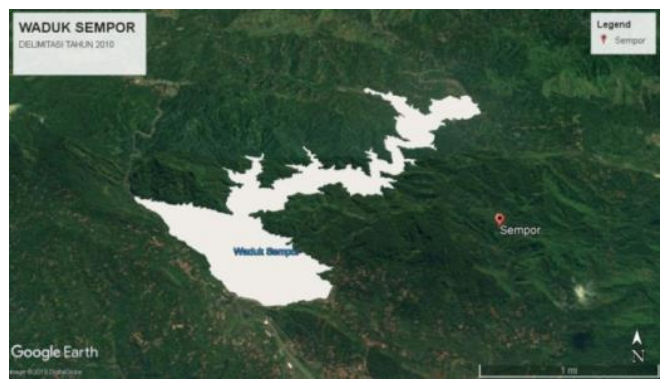

Gambar 2.2. Batas Waduk Sempor pada Citra Google Earth

2. Data teknis Waduk Sempor diperoleh dari Balai Besar Wilayah Sungai (BBWS) Serayu-Opak, Kementrian Pekerjaan Umum dan Perumahan Rakyat RI. Secara umum data teknis Waduk Sempor terdiri dari luasan daerah tangkapan hujan, elevasi muka air, kapasitas tampungan, luas genangan waduk, dan bangunan pelimpah.

3. Data DEM yang digunakan adalah data DEMNAS lembar 1308 dan 1408, diperoleh dari portal BIG yang memiliki resolusi spasial sebesar 2,7 arcsecond atau sekitar 8,5 meter. Pada kegiatan ini cakupan wilayahnya dibatasi oleh DAS Sempor. Data DEMNAS tersebut digunakan untuk menentukan batas DAS, batas waduk, faktor panjang dan kemiringan lereng (LS), serta sebagai data masukan untuk menentukan faktor limpasan permukaan.

4. Data curah hujan diperoleh dari stasiun curah hujan Waduk Sempor. Data berupa data curah hujan harian pada tahun 2018 dengan perekaman dari bulan Januari 2018 sampai Desember 2018. Data ini untuk menentukan faktor limpasan permukaan. Dimana faktor limpasan permukaan diperoleh dari debit puncak dan total volume run off. Data curah hujan harian digunakan untuk menentukan intensitas hujan pada DAS yang merupakan elemen perhitungan debit puncak. Sedangkan data curah hujan tahunan digunakan untuk menghitung total volume run off.

5. Peta Jenis Tanah diperoleh dari Balai Besar Wilayah Sungai Serayu Opak. Jenis tanah Kabupaten Kebumen tersusun dari 5 jenis tanah yaitu aluvial, latosol, litosol, podsolik dan regosol. Peta jenis tanah digunakan untuk menentukan nilai parameter erodibilitas DAS Sempor.

6. Peta Rupa Bumi Kabupaten Kebumen 1:25000, diperoleh dari Portal BIG (http://tanahair.indonesia.go.id/portalweb/

download/perwilayah), dalam bentuk shapefile. Peta RBI ini digunakan sebagai dasar untuk klasifikasi pengunaan lahan secara Supervised.

7. Citra Satelit Sentinel 2A. Citra Sentinel 2A diperoleh dari portal ESA Copernicus (https://scihub.copernicus.eu/

dhus/\#/home). Pengambilan data citra Sentinel 2A disesuaikan dengan tahun pengambilan data curah hujan. Hal tersebut dilakukan agar kesalahan akibat perbedaan waktu perekaman dapat diminimalkan. Data citra Sentinel 2A diambil pada 16 juli 2018, karena nilai tutupan awan dan curah hujan yang rendah. Data Sentinel 2A memiliki ketelitian geometrik 10meter pada kombinasi natural color (band 4-3-2). Citra Sentinel digunakan sebagai data dasar klasifikasi pengunaan lahan dalam penentuan faktor tutupan dan konservasi lahan (CP).

\subsection{Deliniasi DAS}

Pada proses deliniasi DAS terdiri dari beberapa tahapan sebagai berikut ini:

1. Identifikasi arah aliran air permukaan (Flow Direction). Flow direction menggambarkan arah aliran air di permukan tanah berdasarkan perbedaan elevasi piksel dengan identifikasi kecuraman yang tinggi. Setiap sel raster elevasi akan dievaluasi arah alirannya (mengikuti kaidah D8), yang selanjutnya akan diberikan kode arah aliran tersebut. Pemberian kode mengikuti kaidah $2^{\mathrm{n}}(1,2,4,8,16,32,64,128)$. Dimana angka 1 menunjukkan aliran ke arah Timur, 2 ke arah Tenggara, 4 Selatan, dan seterusnya hingga 128 ke arah Timur Laut. Gambaran pengkodean arah aliran disajikan pada Gambar 2.3. Contoh aplikasi penentuan arah aliran disajikan pada Gambar 2.4. 


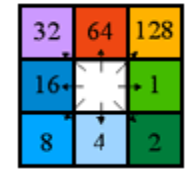

Gambar 2.3. Pemberian kode dalam flow direction (sumber: ArcGIS online)

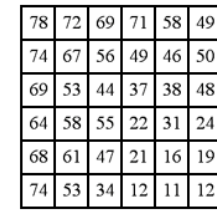

elevation surface

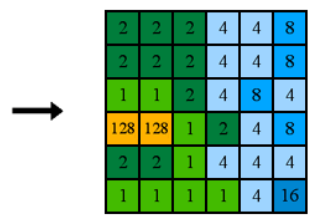

flow direction
Gambar 2.4. Penentuan flow direction (sumber: ArcGIS online)

2. Akumulasi aliran (flow accumulation) menunjukkan besarnya potensi air yang akan terakumulasi pada sebuah piksel saat terjadi hujan. Arah aliran ini juga akan bisa digunakn untuk menentukan pola aliran (stream) dari tempat tertinggi menuju ke jaringan sungai. Flow accumulation dibentuk berdasarkan data flow direction. Prosedur pnentuan flow accumulation ditunjukan pada Gambar 2.5. Berdasarkan gambar tersebut, arah aliran menuju pada elevasi terendah pada masing-masing piksel. Nilai flow accumulation yang besar menunjukkan tempat berkumpulnya air dari area sekitarnya.

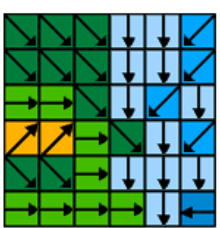

flow direction

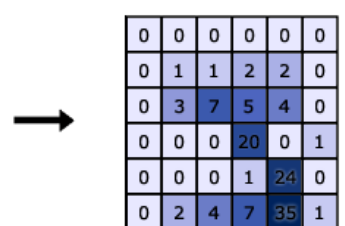

flow accumulation
Gambar 2.5. Ilustrasi flow accumulation (Sumber: ArcGIS online)

3. Stream order menunjukkan kelas aliran air (sungai) yang ditentukan berdasarkan hasil identifikasi flow accumulation. Semakin besar nilai stream order menunjukkan akumulasi air yang masuk pada sungai juga semakin besar. Penentuan stream order ini mengikuti aturan Strahler. Kelas aliran yang ada di kawasan DAS Sempor ditunjukkan pada Gambar 2.6. Gambar 2.6 menunjukkan sungai dengan kelas aliran yang lebih rendah (biru muda), secara gradual akan terakumulasi pada sungai dengan kelas aliran yang lebih tinggi (biru tua). Titik pertemuan antar kelas sungai diidentifikasi sebagai titik tuang (pour point). Titik pour point merupakan tempat terakumulasinya aliran semua air dari stream dibelakangnya sehingga posisi titik pour point bisa digunakan sebagai kerangka pembentukkan DAS. Dalam pekerjaan ini, jumlah pour point yang terbentuk dengan batasan orde 3 sebanyak 46 titik.

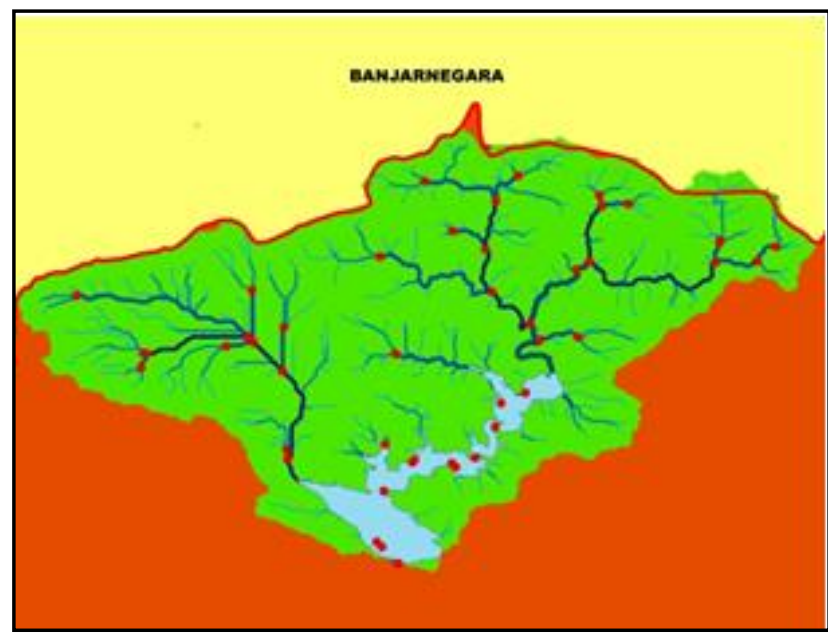

Gambar 2.6. Posisi aliran air dan kelas aliran di DAS Sempor.

Untuk identifikasi area yang lebih kecil dalam rangka evaluasi yang lebih komprehensif, maka posisi titik pour point juga ditempatkan pada semua hulu sungai yang masuk ke tubuh waduk. Area tangkapan air di belakang titik pour point ini disebut sebagai Sub DAS.

Pada deliniasi batas DAS diperlukan data masukan berupa data pour point dan data flow direction. Prinsip pembentukan DAS sama dengan buffer pour point, yaitu dibentuk dari garis yang menghubungkan elevasi tertinggi di sekitar area dengan acuan ketinggian terendahnya.

2.3. Perhitungan kecepatan sedimentasi menggunakan pendekatan Modified Soil Loss Equation (MUSLE)

Metode MUSLE merupakan turunan dari metode USLE, dengan memodifikasi metode USLE agar dapat diterapkan untuk memprediksi sedimen pada daerah tertentu sesuai dengan kondisinya (Nifen, 2016). Perbedaan terdapat pada faktor erosivitasnya. Pada metode MUSLE faktor erosivitas tanah diganti dengan faktor limpasan permukaan tanah dengan memperhitungkan bentuk, kemiringan lereng dan curah hujan, serta kondisi tutupan lahan. Persamaan pendugaan MUSLE dikembangkan oleh Williams (1975) dapat dirumuskan sebagai berikut:

$\mathrm{SY}=\mathrm{Rm} \times \mathrm{K} \times \mathrm{LS} \times \mathrm{CP}$

Keterangan:

SY : jumlah sedimen (Sediment Yield) (ton/tahun)

$\mathrm{Rm}$ : limpasan permukaan/Run off

$\mathrm{K}$ : faktor erodibilitas tanah

LS : faktor panjang dan kemiringan lereng

$\mathrm{CP}$ : faktor tutupan dan konservasi lahan.

Limpasan permukaan/run off (Rm), nilai ini diperoleh dari data curah hujan dan data DEMNAS. Dari data tersebut digunakan untuk menentukkan nilai masukkan perhitungan limpasan permukaan dantaranya luas DAS, koefisien run off, panjang sungai utama, perbedaan elevasi dari titik tertinggi ke terendah, data curah harian dan data curah hujan tahunan. Aliran atau limpasan permukaan merupakan bagian dari air hujan yang mengalir di atas 
permukaan tanah yang masuk ke sungai, danau, waduk, atau laut (Arsyad, 2010). Aliran permukaan ini merupakan bagian dari air hujan yang tidak terabsorsi oleh tanah dan tidak menggenang di permukaan tanah, yang mengalir dari tempat tinggi menuju ke tempat yang lebih rendah. Untuk memperkirakan besarnya aliran permukaan digunakan metode rasional karena dianggap memadai (Murtiono, 2008). Metode ini efektif untuk menentukan nilai aliran puncak dan total volume run off guna kepentingan rancang bangun pencegah banjir, erosi dan sedimentasi (Asdak, 2007). Metode perhitungan aliran permukaan pada persamaan (2) (Williams dan Berndt, 1977).

$\mathrm{Rm}=11,8(\mathrm{Qp} \mathrm{Vp})^{0,56}$

Keterangan:

Qp : aliran puncak (m3/dt).

Vp : total volume run off (m3).

Aliran Puncak (Qp). Aliran puncak merupakan debit aliran air hujan selama mengalir pada DAS. Debit pada umumnya dinyatakan dalam satuan m3/detik. Memperkirakan nilai debit bisa dengan pengukuran langsung di lapangan, pengukuran stasiun pencatat langsung debit, melalui perkiraan data curah hujan, serta melalui data pembangkit debit. Pada kegiatan ini nilai aliran puncak diperoleh dengan persamaan matematis (3) yang diperkenalkan oleh Mulvaney pada tahun 1847(Fleming, 1979).

$\mathrm{Qp}=0,278$ C.I.A.(m3/dt)

Keterangan:

I : intensitas hujan selama time of concentration (mm/jam).

A : luas area DAS $\left(\mathrm{km}^{2}\right)$.

C : koefisien run off. Besarnya koefisien run off (C) didasarkan pada keadaan daerah pengaliran pada Tabel 2.1.

Tabel 2.1. Koefisien aliran permukaan

\begin{tabular}{lc}
\hline Keadaan daerah pengaliran & $\begin{array}{c}\text { Koefisien } \\
\text { run off }\end{array}$ \\
\hline Bergunung dan curam & $0,75-0,90$ \\
Pegunungan tersier & $0,70-0,80$ \\
Sungai dengan tanah dan & $0,50-0,75$ \\
hutan dibagian atas dan & \\
bawahnya & \\
Tanah dasar yang diairi & $0,45-0,60$ \\
Sawah waktu diairi & $0,70-0,80$ \\
Sungai bergunung & $0,75-0,85$ \\
Sungai dataran & $0,45-0,75$ \\
\hline
\end{tabular}

Sumber: Sosrodarsono, 1993

Intensitas hujan selama waktu konsentrasi (Time of Concentration - Tc). Sebelum menentukan intensitas hujan tersebut, dicari nilai waktu konsentrasi untuk DAS yang bersangkutan. Intensitas hujan (I) didapat dari persamaan (4).

$$
\mathrm{I}=\frac{R}{25} \times\left(\frac{24}{T c}\right)^{2 / 3}
$$

Keterangan:

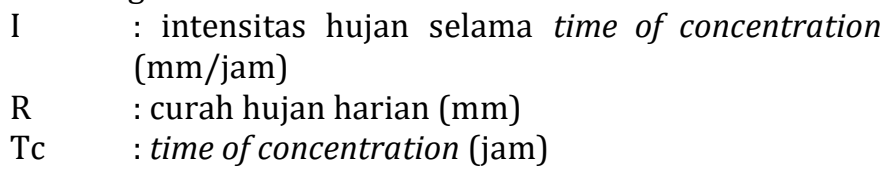

Waktu konsentrasi (Tc) adalah waktu yang diperlukan oleh air dari titik paling jauh (hulu DAS) sampai ke titik pengamatan aliran air/outlet. Salah satu teknik yang digunakan untuk menghitung Tc yang paling umum dilakukan ialah persamaan matematis (5) yang dikembangkan oleh Kirpich (1940).

$$
\mathrm{TC}=\frac{\left(0,869 \times \mathrm{L}^{\mathrm{B}}\right)^{0,885}}{\mathrm{H}}
$$

Keterangan:

Tc : time of concentration (jam)

$\mathrm{L} \quad$ : panjang sungai utama $(\mathrm{km})$

$\mathrm{H}$ : beda tinggi antara titik tertinggi dengan titik terendah pada Sub DAS (m).

Total volume run off merupakan jumlah air yang mengalir pada aliran sungai. Rumus yang digunakan untuk menentukan total volume run off ditunjukkan persamaan (6).

$\mathrm{Vp}=\mathrm{D} \times \mathrm{A} \times \mathrm{CP}\left(\mathrm{m}^{3}\right)$

Keterangan:

D : curah hujan dalam satu tahun (mm/tahun)

A : luas area DAS $\left(\mathrm{km}^{2}\right)$

CP : nilai faktor penutup dan konservasi lahan.

Faktor erodibilitas tanah $(\mathrm{K})$ diperoleh dari peta jenis tanah. Erodibilitas tanah merupakan kemampuan tanah untuk tererosi. Erodibilitas ditentukan oleh topografi, kemiringan lereng, besarnya gangguan oleh manusia, sifatsifat fisik tanah dan pengelolaannya (Arsyad, 2012). Sifatsifat fisik tanah antara lain tekstur tanah, stabilitas agregat tanah, kapasitas infiltrasi, kandungan organik dan kimia tanah. Sifat fisik tanah selalu dinamis dan berubah. Perubahan tesebut disebabkan oleh perubahan waktu dan tata guna lahan ataupun sistem pertanaman. Perubahan karakteristik tanah umumnya terjadi pada waktu hujan, karena pada saat hujan tanah mengalami perubahan orientasi serta karakteristik kimia dan fisik tanah. Peranan tekstur tanah sangat besar terhadap nilai erodibilitas tanah. Untuk mendapatkan nilai erodibilitas rata-rata, menggunakan Tabel 2.2 yang telah dikeluarkan oleh Dinas Rehabilitasi Lahan dan Konservasi Tanah, Departemen Kehutanan. 
Tabel 22. Faktor erodibilitas tanah (K)

\begin{tabular}{lcc}
\hline \multicolumn{1}{c}{ Jenis Tanah } & Faktor K \\
\hline Latosol & coklat kemerahan dan & \\
litosol & & 0,43 \\
Latosol kuning kemerahan dan & \\
litosol & 0,36 \\
Kompleks mediteran dan litosol & 0,46 \\
Latosol kuning kemerahan & 0,56 \\
Latosol & 0,31 \\
Grumusol dan Andosol & 0,20 \\
Aluvial & 0,47 \\
Regosol & 0,40 \\
Podsolik & 0,167 \\
\hline
\end{tabular}

Sumber: Asdak, 2014

Faktor panjang dan kemiringan lereng (LS) dari data DEMNAS. Panjang lereng diukur dari tempat mulai terjadinya aliran air di atas permukaan tanah sampai ke tempat terjadinya pengendapan. Panjang lereng mengacu pada aliran permukaan, yaitu lokasi terjadinya erosi atau kemungkinan terjadinya disposisi sedimen. Kemiringan lereng merupakan ukuran kemiringan lahan relatif terhadap bidang datar yang secara umum dinyatakan dalam persen atau derajat. Kelas kemiringan lereng dapat dilihat pada Tabel 2.3 .

Tabel 2.3. Faktor panjang dan kemiringan lereng (LS)

\begin{tabular}{ccc}
\hline Kelas Lereng & Kemiringan Lereng & LS \\
\hline I & $0-8 \%$ & 0,4 \\
II & $8-15 \%$ & 1,4 \\
III & $15-25 \%$ & 3,1 \\
IV & $25-40 \%$ & 6,8 \\
V & $>40 \%$ & 9,5 \\
\hline
\end{tabular}

Sumber: Kironoto dan Yulistiyanto, 2000

Faktor Tutupan dan Konservasi Lahan (CP) merupakan faktor yang dipengaruhi oleh vegetasi, kondisi permukaan tanah dan pengelolaan area. Faktor tutupan dan konservasi lahan terdiri dari 2 bagian yaitu, faktor tutupan (C) dan faktor konservasi lahan (P), faktor tersebut dijadikan satu apabila data pengolahannya sama. Nilai CP sendiri sangat beragam untuk setiap kawasan maka diperlukan banyak data dalam penentuannya, Perolehan nilai CP dari data peta citra Sentinel 2A yang telah terklasifikasi berdasarkan skema peta rupa bumi Kabupaten Kebumen skala 1:25000. Kriteria penggunaan lahan dan besarnya nilai CP dapat dilihat pada Tabel 2.4.

Tabel 2.4. Faktor tutupan dan konservasi lahan

\begin{tabular}{lc}
\hline Penggunaan Lahan & Faktor CP \\
\hline Air Tawar & 0 \\
Belukar/Semak & 0,3 \\
Gedung & 0 \\
Hutan & 0,03 \\
Kebun & 0,2 \\
Pemukiman & 0 \\
Rawa & 0 \\
\hline
\end{tabular}

\begin{tabular}{lc}
\hline Penggunaan Lahan & Faktor CP \\
\hline Rumput & 0,07 \\
Sawah Irigasi & 0,05 \\
Sawah Tadah Hujan & 0,05 \\
Tegalan & 0,75 \\
\cline { 2 - 2 } Sumber: Departemen Kehutanan, 1986
\end{tabular}

\section{Hasil dan Pembahasan}

Dari hasil deliniasi DAS Sempor diperoleh luas area DAS $43,30 \mathrm{~km}^{2}$. Akumulasi air pada DAS Sempor yang masuk pada waduk melalui sungai. Air yang terbendung pada Waduk Sempor dialirkan melalui outlet yang terdapat pada waduk.

DAS Sempor tersebut membentuk tampungan air. Dari DAS secara keseluruhan terbentuk Sub DAS yang diperoleh dari penetapan elevasi terendah di sungaisungai yang masuk ke waduk. Hasil sub DAS yang terbentuk ditunjukkan pada Gambar 3.1. DAS Waduk sempor menghasilkan 9 Sub DAS dengan pengambilan kelas sungai orde ke 3 .

Pada DAS maupun Sub DAS digunakan sebagai batasan cakupan area atau tampungan air pada hitungan MUSLE. Pada Gambar 3.1 luasan area terbesar berada pada Sub DAS A (area warna coklat) yang mana jaringan sungai yang terbentuk lebih besar dari pada Sub DAS yang lain. Setiap Sub DAS memiliki jaringan sungai yang berbeda karena pendefinisian titik elevasi terendah sebagai titik akumulasi di pertemuan sungai dengan waduk. hal ini sesuai kondisi bahwa air yang berasal dari sungai akan terakumulasi pada titik tersebut.

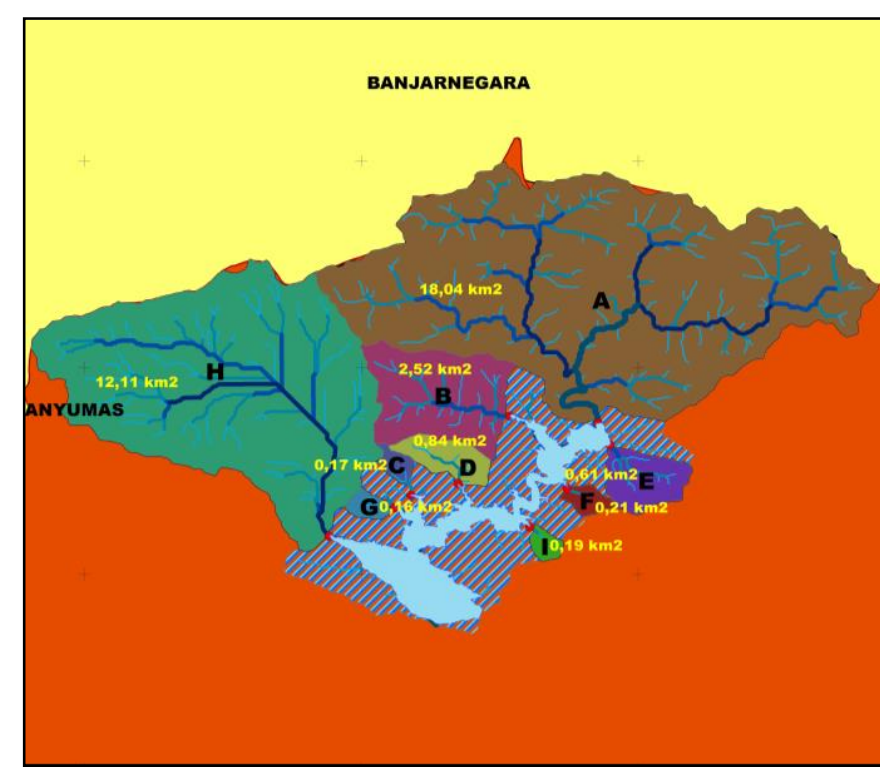

Gambar 3.1. Sub DAS dari Sungai

Penentuan nilai kecepatan sedimentasi baik pada DAS maupun Sub DAS, ditentukan nilai dan faktor berikut:

1. Limpasan permukaan atau run off (Rm). Nilai limpasan permukaan dihitung dengan menggunakan persamaan (2). Limpasan permukaan menunjukkan jumlah volume partikel yang ikut terangkut oleh energi limpasan permukaan. Nilai limpasan permukaan ditentukan oleh aliran puncak dan Total volume run off. 
Data curah hujan yang digunakan yaitu curah hujan tahunan di Waduk Sempor sebesar $3047 \mathrm{~mm} /$ tahun dan curah hujan harian maksimal sebesar 123 $\mathrm{mm} /$ hari di bulan maret. Nilai limpasan permukaan ini sangat dipengaruhi oleh luasan Sub DAS, panjang sungai, dan perbedaan elevasi yang diperoleh dari data DEMNAS sehingga pada DAS keseluruhan memiliki limpasan permukaan 447.629,14ton dan Sub DAS yang mennyumbang limpasan terbesar adalah Sub DAS A dengan alokasi massa 164.077,08 ton.

2. Nilai faktor erodibilitas (K). Nilai faktor erodibilitas diperoleh dari hasil analisis overlay peta jenis tanah wilayah sungai Serayu-Bogowonto dengan peta DAS Sempor. Nilai erodibilitas pada Sub DAS diperoleh dari estimasi nilai erodibilitas dengan presentase luasannya. Pada area DAS Sempor didominasi jenis tanah latosol dan beberapa podsolik. Jenis tanah latosol memiliki nilai erodidibilitas 0,31 dan podsolik memiliki nilai erodibilitas 0,167. Pada keseluruhan DAS sempor memiliki nilai erodibilitas 0,31-0,29.

3. Nilai faktor panjang dan kemiringan lereng (LS). Nilai faktor panjang dan kemiringan lereng diperoleh dari perhitungan data slope. Panjang dan kemiringan lereng dibagi menjadi 5 kelas berdasarkan Tabel 2.3. Secara keseluruhan DAS Sempor didominasi area yang memiliki kemiringan lereng 8-15 \%. Ketika DAS Sempor dibagi menjadi beberapa bagian Sub DAS, maka panjang dan kemiringan lerengnya juga berubah. Semakin sempit suatu area dengan perbedaan ketinggian yang besar menjadikan nilai presentase kemiringan lereng juga semakin besar.

4. Nilai faktor tutupan dan konservasi lahan (CP). Klasifikasi penggunaan lahan dilakukan dengan metode supervised, dengan menentukan training site terlebih dahulu sebagai sampel, sehingga klasifikasi berdasarkan pada nilai digital number-nya. Klasifikasi lahan terbagi menjadi 7 kelas. Nilai faktor tutupan dan konservasi lahan terdiri dari faktor tutupan lahan (C) dan faktor konservasi lahan (P). Pada kegiatan ini faktor $\mathrm{P}$ diasumsikan memiliki nilai 1 (satu) artinya tidak terdapat kegiatan konservasi atau kegiatan yang secara signifikan mengubah penggunaan lahan. Klasifikasi menggunakan data citra Sentinel 2A dengan skema klasifikasi yang sama dengan peta RBI Kabupaten Kebumen 1:25000. Klasifikasi dengan metode supervised secara otomatis melakukan pendefinisian area menggunakan nilai digital number yang sama. Nilai faktor penutup dan konservasi lahan diperoleh dengan mempertimbangkan estimasi luasan area hasil klasifikasi. Untuk kelas penutup lahan memiliki nilai CP sebagai berikut:

a. Badan air, badan air terdiri dari waduk dan sungai pada area tersebut tidak terjadi erosi sehingga memiliki faktor CP 0 .

b. Ladang ditanami tumbuhan palawija dan sebagainya, berdasarkan Tabel 2.4 maka nilai CP untuk ladang adalah 0,75 .

c. Sawah, Waduk Sempor dibangun sebagai sarana irigasi sawah-sawah disana. Luas sawah di Waduk
Sempor 8,87 \% dari keseluruhan luas, berdasarkan Tabel 2.4 maka nilai CP sawah adalah 0,01.

d. Pemukiman terdiri dari bangunan-bangunan di atas tanah sehingga air hujan akan terhalangi oleh atap bangunan. Hal ini mengindikasikan bahwa tidak akan terjadi erosi pada area tersebut, sehingga memiliki nilai CP adalah 0 .

e. Kebun merupakan penggunaan lahan paling dominan di DAS Sempor, lebih dari setengah pengunaan lahan adalah kebun. Mengacu pada Tabel 2.4 penggunaan lahan kebun memiliki nilai $\mathrm{CP}$ adalah 0,2 .

f. Belukar, belukar merupakan lahan yang tidak poduktif berada pada dataran tinggi. Berdasarkan Tabel 2.4 maka nilai CP adalah 0,3.

g. Sedimen merupakan partikel tanah yang tererosi dan terkumpul pada tepian waduk. Sedimen tersebut tersusun oleh partikel tanah yang tidak rapat karena kandungan air yang tinggi, mejadikan tutupan lahan ini sangat mudah terjadi erosi.

Metode pendekatan MUSLE memprediksi kecepatan sedimentasi suatu daerah dengan memperhatikan beberapa faktor yaitu limpasan permukaan, jenis tanah, topografi (panjang dan kemiringan lereng), penutup dan konservasi lahan. Berdasarkan faktor tersebut dilakukan analisis spasial untuk memeperoleh nilai prediksi kecepatan sedimentasi (Kironoto, 2016). Indikator limpasan permukaan semakin menambah parameter pembentukan model DAS tersebut. Semakin banyak parameter-parameter pembentuk maka pemodelan DAS akan mendekati kondisi sebenarnya. Pemodelan geospasial membentuk informasi menjadi kelas-kelas tertentu sehingga memudahkan dalam analisis data.

Hasil akhir berupa estimasi kecepatan sedimentasi sehingga dapat diketahui tingkat laju ketebalan sedimentasi pada DAS. Kecepatan sedimentasi per tahun dinyatakan dengan nilai Sediment Yield (SY) pada persamaan (1). SY merupakan nilai yang menunjukkan jumlah masa sedimen yang terakumulasi per tahun. Penjumlahan SY dilakukan secara langsung dengan asumsi proses sedimentasi dipengaruhi sepenuhnya oleh faktor limpasan permukaan, sehingga secara langsung partikel tanah yang tererosi mengalami sedimentasi. Berdasarkan persamaan SY, DAS Sempor menyumbang sedimen yaitu 166.173,50 ton/tahun. DAS Sempor terdiri dari jenis tanah latosol. Nilai faktor panjang dan kemiringan lereng (LS) pada DAS rata-rata 5,125 , didominasi oleh penggunaan lahan kebun. Selanjutnya untuk mengetahui pengaruh sungai terhadap proses sedimentasi yang terjadi pada DAS Sempor, maka dilakukan perhitungan SY pada Sub DAS yang terbentuk dari sungai.

Luas area Sub DAS terbesar tidak mengindikasikan jumlah sedimen yang juga besar. Hal tersebut dipengaruhi oleh beberapa faktor lainnya, diantaranya faktor erodibilitas, faktor panjang dan kemiringan lereng, serta faktor tutupan dan konservasi lahan. Hasil perhitungan SY pada sub DAS yang terbentuk oleh sungai disajikan pada Tabel 3.1 
Tabel 3.1. Perhitungan total sedimentasi tahunan dengan MUSLE DAS Sempor dari sungai

\begin{tabular}{ccccccl}
\hline $\begin{array}{c}\text { Sub } \\
\text { DAS }\end{array}$ & \multirow{2}{*}{$\mathrm{Km}$} & $\mathrm{K}$ & $\mathrm{LS}$ & $\mathrm{CP}$ & $\begin{array}{c}\text { SY } \\
\text { (ton/tahun) }\end{array}$ & Luas \\
\hline DAS A & $164.077,08$ & 0,31 & 4,63 & 0,321 & $75.595,45$ & 18,04 \\
DAS B & $29.091,34$ & 0,31 & 5,87 & 0,191 & $10.111,06$ & 2,52 \\
DAS C & $5.083,82$ & 0,31 & 9,50 & 0,207 & $3.099,17$ & 0,17 \\
DAS D & $13.384,05$ & 0,31 & 6,22 & 0,199 & $5.135,62$ & 0.84 \\
DAS E & $11.622,09$ & 0,31 & 8,19 & 0,202 & $5.960,48$ & 0.61 \\
DAS F & $6.872,39$ & 0,31 & 8,38 & 0,231 & $4.124,06$ & 0.21 \\
DAS G & $5.933,66$ & 0,31 & 9,50 & 0,249 & $4.351,18$ & 0.16 \\
DAS H & $103.688,70$ & 0,31 & 3,46 & 0,202 & $22.465,73$ & 12.11 \\
DAS I & $5.845,21$ & 0,31 & 8,05 & 0,203 & $2.961,10$ & 0.19 \\
\hline \multicolumn{7}{c}{ Total } \\
\hline \multicolumn{7}{c}{}
\end{tabular}

Berdasarkan Tabel 3.1 Sub DAS yang terbentuk ada 9 area. Dari 9 sub DAS tersebut yang terbesar adalah sub DAS A dengan luas area $18,04 \mathrm{~km}^{2}$, menyumbang sedimen paling banyak yaitu 75.595,45 ton/tahun. Nilai limpasan permukaan (Rm) pada sub DAS A adalah 164.077,08 ton, hal ini berbanding lurus dengan luasan sub DAS tersebut. Nilai erodibilitas sub DAS A sebagian besar tersusun oleh latosol litosol, panjang dan kemiringan lerengnya juga relatif curam dan penutup lahannya didominasi oleh kebun dan ladang.

Merujuk pada hasil perhitungan kecepatan sedimentasi tahunan untuk seluruh DAS Sempor yaitu sebesar $166.173,500$ ton/tahun apabila dikonversi dengan asumsi berat jenis sedimen tanah latosol adalah 1,03 maka volume kecepatan sedimentasi tahunan sebesar 161.333,47 m3/tahun. Berdasarkan data teknis dan informasi yang diperoleh dari Balai Besar Sungai SerayuOpak pada awal pembangunan waduk tahun 1978 diperkirakan mampu menampung air sekitar 52 juta $\mathrm{m}^{3}$, akan tetapi tejadi penyusutan volume tampungan menjadi 38,363 juta $\mathrm{m}^{3}$ pada tahun 1998 , sedangkan pada rentang tahun 1994-1998 jumlah volume yang masuk pada Waduk Sempor adalah 1,488 juta $\mathrm{m}^{3}$. Data terbaru dari BBWSS-O menunjukkan kecepatan sedimentasi yang terjadi di Waduk Sempor pada tahun 2016 yaitu sekitar 160 ribu $\mathrm{m}^{3}$ /tahun. Berdasarkan hasil tersebut kecepatan sedimentasi pada tahun 2016 dan tahun 2018 tidak berbeda signifikan.

Perhitungan kecepatan sedimentasi juga dilakukan pada Sub DAS, diperoleh hasil sebesar 133.803,87 ton/tahun. Hasil tersebut berbeda 32.369,61 ton/tahun dari kecepatan sedimentasi keseluruhan DAS. Proses sedimentasi yang terjadi pada Waduk Sempor sebesar $80,52 \%$ dipengaruhi oleh Sub DAS yang terbentuk dari sungai, sedangkan sisanya secara langsung masuk ke dalam waduk melalui energi limpasan permukaan. Sungai memberikan pengaruh yang besar terhadap sedimentasi, karena secara langsung partikel yang terbawa air menciptakan dinamika sungai baik proses erosi maupun sedimentasi.

Berdasarkan hasil kecepatan sedimentasi pada waduk maka diperoleh ketebalan sedimentasi sebesar 3,7259 $\mathrm{mm} /$ tahun. Perhitungan juga dilakukan pada sub DAS yang mengalir dari sungai, maka diperoleh ketebalan sedimen yang berasal dari sungainya setebal 3,7256 $\mathrm{mm} /$ tahun. Terdapat perbedaan laju ketebalan sedimentasi sebesar 0,0003 $\mathrm{mm} /$ tahun, hal ini menunjukkan sungai memberikan pengaruh yang signifikan terhadap sedimentasi yang terjadi di Waduk Sempor.

Hasil ketebalan sedimen dianggap merata pada keseluruhan waduk, akan tetapi pada kondisi nyata di lapangan ketebalan sedimen tersebut akan terakumulasi pada area tertentu sesuai dengan topografi permukaan dan arus air yang terjadi. Hal tersebut mengakibatkan ketebalan sedimen di dalam waduk bervariasi (Cahyono, 2017). Pada umumnya sedimen berkumpul pada tepian waduk pada area inlet. Hal ini dikarenakan ketika partikel tanah yang tererosi bersama aliran air memasuki tengah waduk energinya semakin berkurang sehingga partikel tanah akan terakumulasi pada tepian waduk. Besarnya ketebalan sedimen juga dipengaruhi oleh jenis tanah yang tererosi.

Sedimentasi pada Waduk Sempor mengalami penurunan dari tahun ke tahun menunjukkan kinerja pemerintah dalam perbaikan dan rehabilitasi sungai. Berdasarkan hasil estimasi hitungan ketebalan sedimentasi yang terjadi di Waduk Sempor, dikategorikan dalam kelas sedang berdasarkan ketentuan Departemen Kehutanan Tahun 2009. Perhitungan kecepatan sedimentasi dengan menggunakan metode MUSLE dapat memberikan gambaran kecepatan sedimentasi secara kasar yang berupa hasil prediksi.

Nilai hasil kecepatan sedimentasi tersebut memberikan gambaran kondisi fisik Waduk Sempor sebagai acuan dalam pengambilan keputusan oleh pihak pengelola waduk dalam kegiatan perencanaan maupun pengelolaan waduk di antaranya kegiatan rehabilitasi irigasi pada area DAS ataupun pengerukan cek Dam. Hal tersebut dilakukan guna menjaga kesehatan waduk sehingga usia layanan Waduk Sempor optimal.

\section{Kesimpulan}

Berdasarkan hasil dan pembahasan sebelumnya maka kesimpulan yang diperoleh dalam kegiatan ini adalah:

1. Kecepatan sedimetasi pada Waduk Sempor pada tahun 2018 dengan menggunakan metode pendekatan MUSLE sebesar 166.173,500 ton/tahun.

2. Sungai memberikan pengaruh sedimentasi yang besar terhadap sedimentasi pada DAS Sempor secara keseluruhan yaitu sebesar 80,52\%. Area sungai menyumbang laju ketebalan sedimentasi sebesar 3,7256 $\mathrm{mm} /$ tahun dari total laju ketebalan sedimen $3,7259 \mathrm{~mm} /$ tahun (pengaruh area non sungai hanya $0,0003 \mathrm{~mm} /$ tahun). Hal tersebut menunjukkan bahwa keberadaan sungai memberikan pengaruh yang signifikan terhadap sedimentasi pada waduk.

3. Berdasarkan ketentuan Departemen Kehutanan Tahun 2009 tentang klasifikasi laju ketebalan sedimentasi Waduk Sempor masuk ke dalam kategori sedang dengan laju ketebalan 3,7259 mm/tahun. 


\section{Pernyataan Konflik Kepentingan}

Penulis menyatakan tidak ada konflik kepentingan dalam artikel ini (The authors declare no competing interest).

\section{Referensi}

Arsyad, S. (2010). Konservasi Air dan Tanah. Bogor: IPB Press.

Arsyad, S. (2012). Konservasi Tanah dan Air, (edisi Kedua, Cetakan Ketiga). Bogor: IPB Press.

Asdak, C. (2007) Hidrologi dan Pengelolaan DAS. (cetakan keempat).Yogyakarta: Gadjah Mada University Press.

Asdak, C., 2014, Hidrologi dan Pengelolaan DAS (cetakan keenam). Yogyakarta: Gadjah Mada University Press.

Cahyono, B.K., Lukman H., Waljiyanto, Agus D.A. (2017). Perhitungan Kecepatan Sedimentasi Melalui Pendekatan Usle dan Pengukuran Kandungan Tanah dalam Air Sungai yang Masuk ke dalam Waduk Sermo.

Banuwa, I. I. S., \& Si, M. (2013).Erosi. Prenada Media.

Fleming. (1979) Deterministic Models in Hydrology, FAO. Rome, Italy.

Geospasial, Badan Informasi. (2015). DEMNAS. Diakses dari http://tanahair.indonesia.go.id/portal pada tanggal 11 Juli 2018

European, Space Agency. (2018). Sentinel 2A. Diakses dari https://scihub.copernicus.eu/dhus/\#/home pada tanggal 11 Juli 2018 web/download/perwilayah.

Kehutanan, D. (1986). Pedoman Penyusunan Pola Rehabilitasi Lahan dan Konservasi Tanah.
Direktorat Jendral Reboisasi dan Rehabilitasi Lahan. Jakarta.

Kehutanan, K. (2010). Rencana Strategis 2010-2014 (ID). Jakarta: Kementerian Kehutanan.

Kehutanan, Kementerian, 2015, Rencana Strategis 20152019 (ID). Jakarta: Kementerian Kehutanan.

Kirpich, Z. P. (1940). Time of concentration of small agricultural DAS,10(6). 362 Civil engineering.

Kironoto, B. A., \& Yulistiyanto, B. (2000). Konservasi lahan. Yogyakarta: Gadjah Mada University Press.

Murtiono, U. H. (2008). Kajian Model Estimasi Volume Limpasan Permukaan, Debit Puncak Aliran, Dan Erosi Tanah Dengan Model Soil Conservation Service (SCS), Rasional Dan Modified Universal Soil Loss Equation (MUSLE) Studi Kasus di DAS Keduang, Wonogiri, (Vol. 22, No. 2, pp. 169-185), In Forum Geografi.

Nifen, S. Y., Kironoto, B. A., \& Luknanto, D. L. (2016). Kajian Erosi Dengan Metode MUSLE Daerah Tangkapan Hujan Waduk Sermo Kabupaten Kulon Progo. Daerah Istimewa Yogyakarta: Jurnal Teknik Sipil ITP ISSN 2354-8452, 3.

Sosrodarsono. (1993). Hidrologi Untuk Pengairan. Jakarta: Pradaya Paramita.

Williams, J. R. (1975). Sediment routing for agricultural watersheds 1. JAWRA Journal of the American Water Resources Association, 11(5), 965-974.

Williams, J. R. and Berndt, H.D. (1977). Sediment Yield Prediction Based on Watershed Hydrology. Transactions of the American Society of Agricultural and Biological Engineers, 20, 1100-1104. 